\title{
A microcomputer-based system for continuous measurement of rodent food intake
}

\author{
RAY T. STERNER \\ U.S. Fish and Wildlife Service, Denver Wildlife Research Center, Denver, Colorado 80225
}

\begin{abstract}
A microcomputer-based system is described for the automatic acquisition, storage, and analysis of rodent food intakes. The feed-o-meter provides reliable, valid measurements of consumption, with minute-by-minute accuracy of $>.03 \mathrm{~g}$.
\end{abstract}

Numerous descriptions of equipment for monitoring the continuous eating patterns of rats have been published: (1) strain gauge devices (Armstrong \& Coleman, 1979; Le Magnen \& Devos, 1970; Le Magnen \& Tallon, 1966), (2) contact-type circuits (Beauchamp, Donovick, \& Burright, 1972; Fallon, 1965; Morrison \& Coffey, 1973; Strohmayer, Silverman, \& Grinker, 1980), (3) leverpress systems (Belagura \& Coscina, 1969; Kisseleff, 1970; Panskepp, 1973; Thomas \& Mayer, 1968), and (4) photocell systems (Davies, 1977; Morrison \& Coffey, 1973; Yanura \& Suzuki, 1979). To date, however, almost all of these approaches have utilized chart-paper recorders for documentation of response patterns, an approach involving labor-intensive analysis. The contact and photocell systems equate rodent proximity to food cups as consumption, and many of the leverpress systems utilize pellet dispensers, devices that may assess operant or hoarding responses rather than actual ingestive behaviors.

Developments in the electronic and computer industries have yielded hardware applicable to the continuous measurement of food intake by rodents. Modern electronic balances obviate the fabrication of elaborate strain gauge devices (Armstrong \& Coleman, 1979; Le Magnen \& Tallon, 1966), and increased memory capacities of recent microcomputers (i.e., 24-96 KB), coupled with numerous storage peripherals, make chartpaper recorders obsolete.

In the system described here, dry weights of individual food cups are monitored by means of electronic analog-digital balances that are dedicated to a Z-80A incorporated microprocessor. Times and magnitudes of

This research was supported with funds provided to the U.S. Fish and Wildlife Service by the U.S. Agency for International Development, under the project "Control of Vertebrate Pests" (ID/TAB-473-1-67). I thank Don Muntyan (Scientech, Inc.), Don Lewis ( $L$ \& $\mathrm{L}$ Enterprises), and Terry Sund (Symbolics, Inc.) for engineering and software assistance. Additionally, John De Grazio and R. Daniel Thompson were instrumental in securing project funds, and Kenneth Crane set up the auxiliary food measurement equipment and assisted with data collection. References to trade names do not imply government endorsement of commercial products. Requests for reprints should be addressed to Denver Wildlife Research Center, Building 16, Federal Center, Denver, Colorado 80225. weight removals (food consumption) are stored on floppy diskettes for later analyses with auxiliary BASIC language programs or commercial file management/ statistical analysis systems.

\section{DESCRIPTION OF THE SYSTEM}

The system is composed of two main elements, hardware (which includes microcomputer and peripheral equipment and auxiliary food measurement equipment) and software (see Figure 1). Essentially, remote-sensor electronic balances hold food cups in front of individual rat-housing cages. These are connected by a multiplexer/ demultiplexer to a microcomputer having dual floppy diskettes. Peripherals include a CRT display with keyboard, printer, and phone modem. Special cage modifications allow rodents access to one or two food cups while preventing escape of the animals and distortion of sensors. Software governs the automatic collection, storage, and analysis of temporal changes in sensor weights (i.e., food removals).

The system was built to my specifications by Scientech, Inc. (Boulder, Colorado). Several hardware and software modifications were provided by $\mathbf{L} \& \mathbf{L}$ Enterprises (Arvada, Colorado), and a program option for collecting two-choice food-preference data was prepared by Symbolics, Inc. (Lakewood, Colorado).

\section{Microcomputer and Peripheral Equipment}

The microcomputer and peripheral equipment consist of six main components: (1) four Scientech 3300-08 analog/digital electronic balances with remote sensors (Scientech, Inc.), (2) a Scientech 303 octaport multiplexer/demultiplexer (Scientech, Inc.), (3) a Northstar HORIZON II microprocessor with floppy diskette storage (North Star Computers, Inc., Berkeley, California), (4) a Hazletine 1500 CRT video display terminal (Hazletine Corporation, Greenlawn, New York), (5) a TI 820-RO printer (Texas Instruments, Inc., Houston, Texas), and (6) an AD-342 Anderson-Jacobson modem (Anderson-Jacobson, Inc., San Jose, California). Specific items were selected because of efficiency, reliability, or cost, but all equipment is RS-232-C compatible.

Scientech 3300-08 balances. Each 3300-08 electronic 


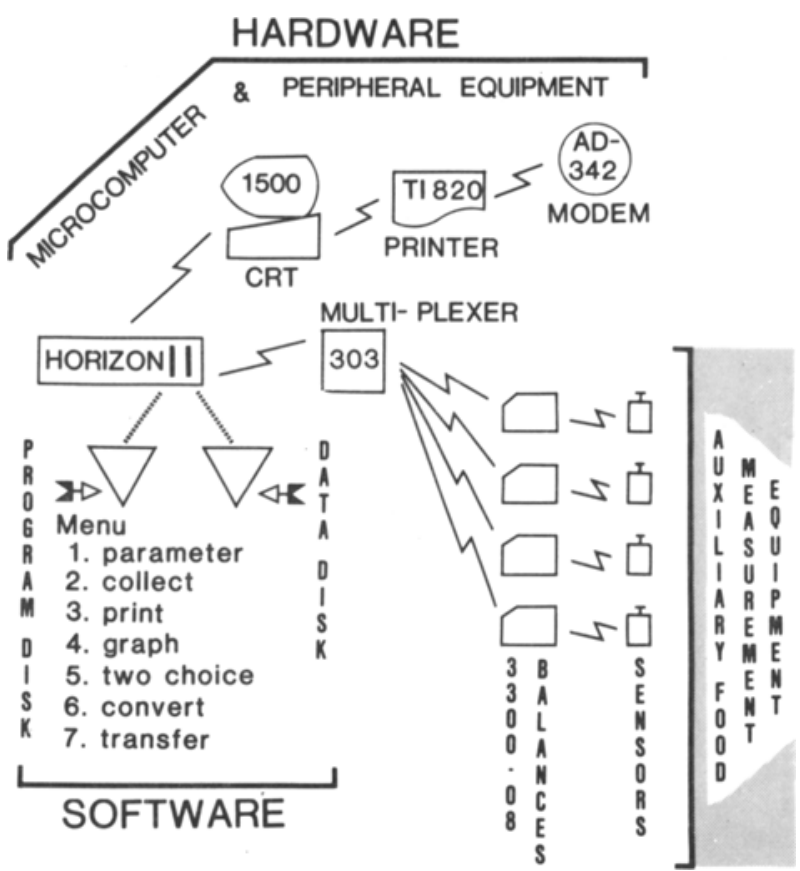

Figure 1. Schematic illustration of the rodent feed-o-meter system.

balance is a dual range (i.e., $0-20 \mathrm{~g}$ or $0-200 \mathrm{~g}$ ), analog/ digital instrument. The present application uses four balances operating in the $0-$ to $200 \mathrm{~g}$ range with $\mathrm{BCD}$ coded 1-2-4-8 parallel TTL logic (i.e., inclusion of eight balances per octaport is possible). Each balance consists of a chassis $(11.4 \times 18.7 \times 27.9 \mathrm{~cm} ; 5.5 \mathrm{~kg}$; sevensegment, five-character LED digital readout) and a cylindrical remote sensor $(5.75 \times 3.25 \mathrm{~cm}$ in diameter; $1.24 \mathrm{~kg}$ ). The hard-wired sensor allows automatic monitoring of a food cup up to $8 \mathrm{~m}$ from the chassis.

An important feature of the balances is the "weightaveraging" function. This programmable function allows the user to set each balance to compute a mean weight per sampling interval, with an average weight derived from numerous within-interval readings of 1 - to $85-\mathrm{sec}$ durations. The advantage of weight averaging is the attenuation of extraneous vibrations.

Scientech 303 octaport. The multiplexer/demultiplexer provides an interface between the HORIZON II and Scientech balances. The octaport has eight bitserial connectors and four bit-parallel connectors. The serial connectors have transmit, receive, clear-to-send, and secondary clear-to-send lines as defined by RS-232-C specifications. The serial data rate is selectable from 110 to 9,600 baud, but a uniform baud rate is required among components. Two of the parallel connectors serve as input connectors and have eight input bits, a latch bit, and two output bits; the other two serve as output connectors with eight output bits and four undedicated input bits. Parallel lines are TTL compatible; serial lines are RS-232-C compatible.
HORIZON II microcomputer. The Northstar HORIZON II is the main control unit of the system and utilizes a Z-80A microprocessor. Several important specifications of the computer are: S-100 bus structure, 4- $\mathrm{MHz}$ internal clock, two Shugart SA400 minifloppy diskette storage drives (Shugart Associates, Sunnyvale, California), 32-KB fully static memory, and Northstar DOS 4.0 (disk operating system) with an ExtendedBASIC language (North Star, Note 1). All software and hardware functions are controlled by the HORIZON II.

Hazletine 1500 video display terminal with keyboard. The Hazletine 1500 CRT with keyboard is the main communications link between the user and other system hardware. The terminal displays up to 2480 -column lines of ASCII-coded characters. All program generation, system operation, and hardware operation are input and monitored by this terminal.

TI 820-RO printer. All printed output is handled by the Texas Instrument 820 receive-only terminal. This is a microprocessor-based impact-type printer (i.e., 9 by 7 matrix/character font; $150 \mathrm{cps}$ ).

Anderson-Jacobson AD-342 modem. Telephone transmission of diskette-stored data is possible by means of the Anderson-Jacobson AD-342 modem at selected rates (i.e., $0-450$ baud). This device is wired in series with the Hazletine 1500, Scientech 303 octaport, and HORIZON II. Rate of transmission is governed by baud switches, but it must be the same among peripherals and agree with JCL specifications of commercial data file management systems.

\section{Auxiliary Food Measurement Equipment}

The rat-housing cage and auxiliary equipment are illustrated in Figure 2. Each rat is housed in an individual wire-mesh cage $(25 \times 20 \times 18 \mathrm{~cm})$ supported $25 \mathrm{~cm}$ above a tabled surface by separate mounting stands $(30 \times 25 \times 50 \mathrm{~cm})$. An approximately $10-\mathrm{cm}^{2}$ port is cut in the lower center of each cage front. A Plexiglas cylinder $(.3 \times 15 \times 9 \mathrm{~cm}$ in diameter $)$ is mounted to the cage front, with an approximately $10-\mathrm{cm}^{2}$ opening in the Plexiglas aligned directly over the "food port" of the wire cage. The top of this cylinder is sealed with $.3-\mathrm{cm}$ Plexiglas $(9-\mathrm{cm}$ in diameter). The bottom is fitted with an $8-\mathrm{cm}$-diameter stainless steel food guard having a concave surface to a $3.3-\mathrm{cm}$-diameter opening; this guard is held in position by a hose clamp that compresses the bottom of the Plexiglas cylinder. Together, these cage alterations allow each rat access to the food cup but prevent escape and minimize sensor distortion during feeding.

Each sensor holds a cylindrical Pyrex food cup (No. 3140; $5 \mathrm{~cm}$ high $\times 7 \mathrm{~cm}$ in diameter). Each cup is glued to a shallow plastic dish $(.75 \mathrm{~cm}$ deep $\times 9 \mathrm{~cm}$ in diameter) that serves to catch spillage. A laboratory support jack ("Big Jack," Precision Scientific, Chicago, Illinois) holds the sensor and cup beneath the food guard. Each jack rests on a $2.5-\mathrm{cm}$-thick foam rubber 


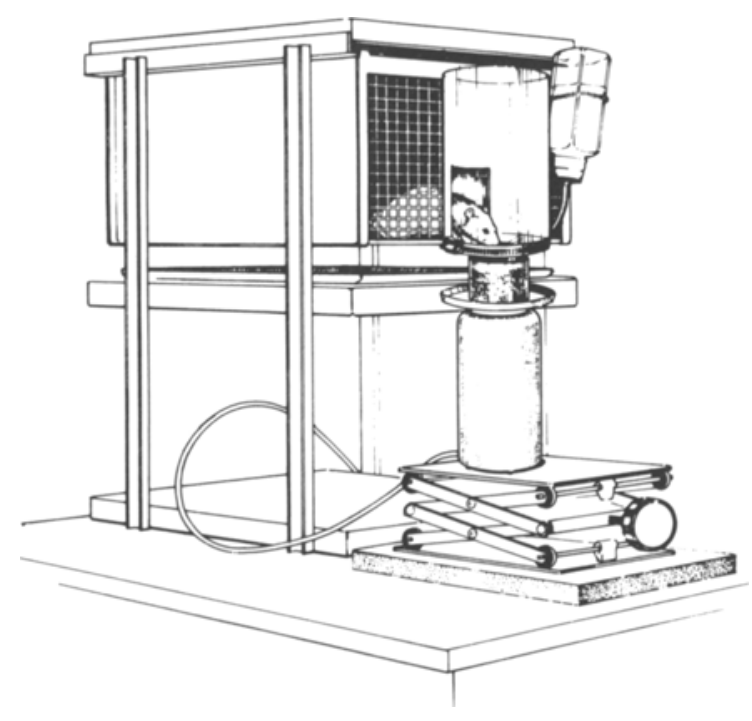

Figure 2. Detail of the auxiliary food measurement equipment used to position the sensor and food cup in front of the rat-housing cage.

pad to reduce vibration of the sensors. Sensors and cups must be positioned carefully (i.e., avoid contact with other surfaces) to ensure error-free recording. Sizing of the "food port" is also critical to prevent rodents" crawling onto the food guard, thereby distorting the sensors.

\section{Software}

Data acquisition, storage, and reduction is governed by an Executive Program (MENU) that offers a choice of seven user options: (1) parameter-file maintenance, (2) collect data, (3) print data, (4) graph data, (5) twochoice data, (6) convert data, and (7) transfer data to modem. All of these programs are written in an interactive mode, and the user specifies a set of parameters with the Hazletine 1500. A short description of each routine follows.

Executive program (Menu). Menu is a 38-line control program that governs the loading of seven optional data collection, conversion, and analysis programs into memory. A copy of Menu is listed in Part 1 of the appendix. Lines 70-130 inclusive show the PRINT statements displayed as seven options for the user. Following depression of the numbered option on the Hazletine 1500 keyboard, Menu "CHAINS" to the selected program, and, upon completion, each program "CHAINS" back to Menu.

Parameter-file maintenance (Option 1). This is a 300-line program that stores data identifiers (header information) on the data diskette. Ten identifiers are requested and stored: password (i.e., $\leqslant 10$ characters used for file security), title (i.e., $\leqslant 20$ characters of descriptive information about the study), date (i.e., MM/DD/YY numeric code for date), scan interval (i.e., $\leqslant 2$-digit numeric that specifies the number of minutes elapsing between scans of the balances), $\mathrm{min}$ / max change-in-state criteria (i.e., numeric values that specify the minimum and maximum weight, in grams, difference used to record food consumption), low/ high graph value (i.e., numeric values that specify the minimum and maximum weight differences used as bounds of the abscissa by the graph program), and lighton/off times (i.e., two HH:MM times that specify the diumal light-dark schedule used during data collection).

No real-time clock functions are available. Scan intervals accurate to $1 \mathrm{~min}$ (i.e., range $=1.60 \mathrm{~min}$ ) are handled by counter circuits. Numerous error-detection loops and diagnostics are included; these account for much of the program's length.

Collect data (Option 2). The data collection program is a 314-line program that compares and stores weight differences occurring for each balance (sensor) at specified scan intervals. Functions of this program include addressing of the octaport (Scientech 303) and data handling (i.e., serial/parallel bit conversion and test), monitoring of time (i.e., scan interval), and comparing of balance weights to prior weights and the change-instate criterion.

Collect data also offers the user three subroutines: collect, wait, and exit to Menu. The collect subroutine (see Part 2 of the appendix) specifies that each balance will be scanned for the remaining weight after a specified interval obtained from parameter-file maintenance. This weight is then subtracted from the previous lowest recorded weight and compared to the change-in-state criterion entered in the parameter file. If this difference exceeds criterion, the time, sensor, and magnitude of difference (in milligrams) are stored onto the data diskette; otherwise, no new data are recorded, but time is updated and scan interval is reinitiated. The wait subroutine simply precludes read/write operations until collect is reinitiated, a useful function to allow care of animals. Exit to Menu is self-explanatory.

Print data (Option 3). This is an 89-line program that prints the data recorded by the collect data program. Output includes (1) select header information, (2) spurious data entries, (3) times and amounts of food consumption (in milligrams) recorded for each balance, and (4) sums of the weight differences recorded for each balance.

Graph data (Option 4). This is a 101-line program that generates a histogram plot of the food-intake profile for each rat. The abscissa is specified in equal increments bounded by the minimum and maximum weights (in milligrams) cited in the parameter-file program. The ordinate represents numbers of scan intervals during which weight differences of specified magnitudes were recorded.

Two-choice data (Option 5). This 240-line program controls the collection and printing of food-intake measurements during a two-choice preference test. Change-in-state data are stored for two sensors representing a single rodent.

Convert data (Option 6). The convert data program 
is a 96-line program designed to reorder data collected using two-choice preference. Data for each sensor are copied to a "scratch disk" for printing in the collect data mode.

Transfer data to modem (Option 7). The modem option loads a 52-line program into memory that addresses the octaport to the Anderson-Jacobson modem. Data are transmitted at 300 baud by means of phone line for subsequent analysis or storage using commercial data file/statistical systems (e.g., SAS, SPSS).

\section{EXPERIMENTAL USE OF THE SYSTEM}

Eight tests were conducted to determine the operating characteristics and effectiveness of the system. Each balance was calibrated at the start of tests by using standard laboratory weights; the weight-average function of balances was suppressed throughout these procedures.

\section{Validity (Tests 1 and 2)}

Tests 1 and 2 were each 4 -h validation tests conducted to verify that data stored on floppy diskette (i.e., collect data) were valid measurements of the weight removed from system balances. For both tests, balances were zeroed and the sensors were loaded with cups containing about $150 \mathrm{~g}$ of dried sand. Next, the collect data program was initiated at a scan interval of $1 \mathrm{~min}$; the change-in-state criterion was .01 and $.05 \mathrm{~g}$ for respective tests. Fifty times throughout each test small quantities of sand (Test 1: mean $=.11 \mathrm{~g}, \mathrm{SD}=$ $.06 \mathrm{~g}$, range $=.03-.32 \mathrm{~g}$; Test $2:$ mean $=.12 \mathrm{~g}, \mathrm{SD}=.05 \mathrm{~g}$, range $=.03-.26 \mathrm{~g}$ ) were removed from each cup. The time and amount of each removal were recorded by the investigator onto a data sheet.
Differences between the data stored on the diskette and those recorded by the investigator were tabulated for each test (Table 1). As shown, $96 \%$ and $99 \%$ of these measurements were $\leqslant .02 \mathrm{~g}$ discrepant in Test 1 and 2, respectively. Moreover, with the exception of seven removals that were $<.05 \mathrm{~g}$ (Test 2 ) and eight removals that occurred at the time balances were scanned, times of removals were recorded correctly on the diskette. These results validate both hardware and software functions associated with data acquisition.

\section{Stability and Accuracy (Tests 3-7)}

Three observations relevant to system accuracy were made during Tests 1 and 2. First, recording changes of $.01 \mathrm{~g}$ yielded 103 false positive and 81 false negative fluctuations (see Table 1). This instability of measurements was attributed to uncontrolled electronic (e.g., heat, voltage), mechanical (e.g., vibration), and meteorological (e.g., humidity, air currents) factors. Although fluc tuations generally occurred as alternate $.01 \mathrm{~g}$ increases and decreases in weight, several .02- to .03-g fluctuations also occurred. Additionally, minor "drift" of balance weights accrued from these fluctuations (i.e., $\leqslant .08 \mathrm{~g} /$ 4-h test). Second, no spontaneous fluctuations were recorded during Test 2 (i.e., $.05 \mathrm{~g}$ change in state). This result showed that spontaneous fluctuations of balance weights could be overridden by appropriate programming. Third, removing weight from balance sensors during the approximately 5 -sec scanning period caused eight data values to be combined into the subsequent scan interval (i.e., delayed $1 \mathrm{~min}$ ).

Based on these observations, Tests $3,4,5,6$, and 7 were conducted to better quantify the system's stability and accuracy during a 24-h period. Standard weights of approximately $150 \mathrm{~g}$ of dried sand were placed on each

Table 1

Summary of Validation Data

\begin{tabular}{|c|c|c|c|c|c|c|c|}
\hline \multirow[b]{2}{*}{ Balance } & \multicolumn{5}{|c|}{ Investigator- and System-Recorded Agreement } & \multicolumn{2}{|c|}{ Fluctuation } \\
\hline & Equal & $\pm .01 \mathrm{~g}$ & $\pm .02 \mathrm{~g}$ & $\pm .03 \mathrm{~g}$ & $\pm .09 \mathrm{~g}$ & $.01 \mathrm{~g} \mathrm{FP}$ & $.01 \mathrm{~g} F \mathrm{~F}$ \\
\hline \multicolumn{8}{|c|}{ Test $1: .01 \mathrm{~g}_{\Delta-\text { state }}$} \\
\hline 1 & 20 & 23 & 5 & 2 & & 25 & 23 \\
\hline 2 & 31 & 13 & 3 & 3 & & 17 & 9 \\
\hline 3 & 28 & 21 & 1 & 0 & & 28 & 24 \\
\hline 4 & 13 & 23 & 10 & 4 & & 33 & 25 \\
\hline$\Sigma$ & 92 & 80 & 19 & 9 & & 103 & 81 \\
\hline$\%$ & 46 & 86 & 96 & 100 & & & \\
\hline \multicolumn{8}{|c|}{ Test $2: .05 \mathrm{~g}_{\Delta \text {-state }}$} \\
\hline 1 & 22 & 19 & 4 & 1 & 1 & 0 & 0 \\
\hline 2 & 24 & 10 & 4 & 0 & & 0 & 0 \\
\hline 3 & 33 & 13 & 3 & 0 & & 0 & 0 \\
\hline 4 & 19 & 20 & 10 & 0 & & 0 & 0 \\
\hline$\Sigma$ & 98 & 62 & 21 & 1 & 1 & 0 & 0 \\
\hline$\%$ & 54 & 80 & 99 & 99 & 100 & & \\
\hline
\end{tabular}

Note $-F P=$ false positive, $F N=$ false negative; $\%=$ cumulative percentage. Removals for Test 2 do not sum to 50 per balance. This is due to three, two, one, and one removals of <.05 g occurring for Balances $1,2,3$, and 4, respectively. These data are not lost, but they are combined into the subsequent scan interval, in which a total removal of $\geqslant .05 \mathrm{~g}$ is detected. 
sensor, and the collect data program initiated. All of these tests involved a 1-min scan interval, whereas change-in-state criteria were designated at $.01, .02$, $.03, .04$, and $.05 \mathrm{~g}$ during respective tests.

Balance recordings were "smoothed" as the changein-state criteria increased. Mean (and standard deviation) spontaneous fluctuations across the four balances were $274.5(88.8), 14.8(20.9), 1(1.2), 1(2)$, and $0(0)$ during the $.01-, .02-, .03-, .04-$, and $.05-\mathrm{g}$ criterion tests, respectively. Average (and standard deviation) "drift" of balance weight was $.03(.02), .06(.05), 0,0$, and 0 for these tests. Of 1,095 recorded fluctuations in the five tests, 91\% occurred in Test 3 (i.e., .01-g criterion). Only four fluctuations occurred using the .03- and .04-g criteria, with "drift" cancelled over the 24-h period. As in Test 2, fluctuations were eliminated by using the $.05-\mathrm{g}$ criterion, as well as with the .04 -g value (i.e., Tests 6 and 7). Thus, the programmed change-instate parameter overrides system instabilities, allowing minute-by-minute measurement accuracy of $\geqslant .03 \mathrm{~g}$.

\section{Effectiveness (Test 8)}

Test 8 was conducted to demonstrate the operational use of the "feed-o-meter." Briefly, I monitored the minute-by-minute food intakes of eight male SpragueDawley albino rats (Charles River Laboratories, Wilmington, Massachusetts) for 3 consecutive days. The procedure involved single-choice presentation of ground Purina Rat Chow. Test cages were in a partially soundproof, temperature-controlled $\left(20^{\circ} \mathrm{C}-23^{\circ} \mathrm{C}\right)$ room. A $12: 12 \mathrm{~h}$ light-dark schedule (i.e., $0800-1959 \mathrm{~h}$ and 2000-0759 h, respectively) was maintained before and during the test. Rats were allowed 4 days adaptation to test cages. Ad-lib feeding patterns were measured during consecutive $23-\mathrm{h}$ periods daily (i.e., 0900-0759 h), with maintenance of rats and data files occurring between $0800-0859 \mathrm{~h}$. Sensors were loaded daily with a glass food cup containing approximately $150 \mathrm{~g}$ of chow, and the collect data program was initiated using a scan interval of $1 \mathrm{~min}$ with a change-in-state criterion of $.05 \mathrm{~g}$.

Mean (and standard error) daily food intake was $20.5 \mathrm{~g}$ (.24) and occurred during a daily average of $92.9 \mathrm{~min}$ (4.1) of eating. As expected, a strong nocturnal effect was evident; $74 \%$ of the 3-day consumption and $80 \%$ of all ingestion times (in minutes) were recorded during the "dark" segments of the light schedule. Spillage was monitored by weighing the daily amounts of food in the "catch plates" (see Figure 2); this averaged $.53 \mathrm{~g}(\mathrm{SE}=.12$, range $=.09-1.75)$ per day, values that minimally affected eating patterns.

Figure 3A shows the minute-by-minute food consumption patterns of the eight rats, and Figure 3B is an enlargement of the 2200- to 0130-h portion of Rat 1's record for Day 1. Note the distinct "meals" characterizing these data. Data for Rats 1-4 show consistent intakes of several 20 - to $60-\mathrm{min}$ meals during the dark period,
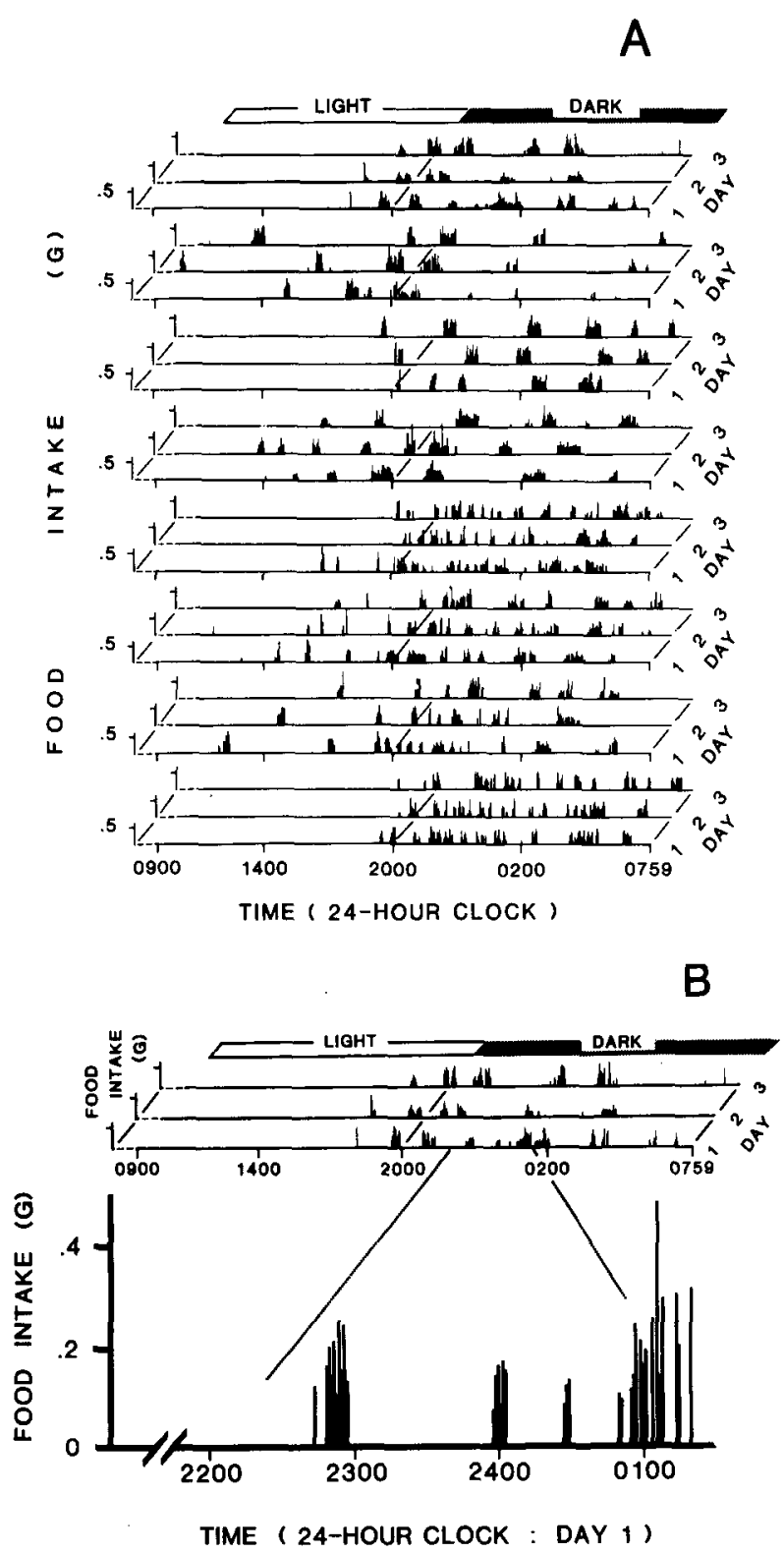

Figure 3. (A) Minute-by-minute food-intake patterns of eight albino rats during the 3-day ad-lib feeding test (i.e., Rat $1=$ top . . Rat 8 = bottom). (Note-The dashed portion of each abscissa refers to the 1-h maintenance period between $0800 \mathrm{~h}$ and $0859 \mathrm{~h}$ daily; no food consumption measurements were recorded during this period.) (B) Enlargement of the consumptions by Rat 1 between $2200 \mathrm{~h}$ and $0130 \mathrm{~h}$ of Day 1 .

whereas patterns of Rats 5-8 indicate more frequent, shorter meals.

Numerous prior studies have shown that rats are not random feeders (Belagura \& Coscina, 1969; Le Magnen \& Devos, 1970; Le Magnen \& Tallon, 1966; Levitsky, 1970; Panskepp, 1973). Data for albino rats have indicated that $60 \%-70 \%$ of daily food intake is ingested as 6-12 meals during the nocturnal portion of the circadian cycle (Belagura \& Coscina, 1969; Kisseleff, 1970). Although definitions of "meals" vary among investi- 
gators, the observed nocturnal and meal-eating patterns agree sufficiently with earlier reports (i.e., Kisseleff, 1970; Le Magnen \& Tallon, 1966; Panskepp, 1973) to confirm efficacy of the system.

\section{REFERENCE NOTE}

1. North Star. System software manual (North Star Computers Soft-Doc Revision 2.1). Berkeley, Calif: Author, 1979.

\section{REFERENCES}

Armstrong, S., \& Coleman, G. A strain gauge device for measuring feeding or drinking in laboratory rats. Physiology \& Behavior, 1979, 23, 1153-1156.

Beauchamp, J., Donovick, P. J. \& Burright, R. G. An automated system for long term and continuous computer compatible recording of feeding, drinking and general activity behaviors of rodents. Physiology \& Behavior, 1972, 8, 765-768.

Belagura, S., \& Coscina, D. V. Influence of gastrointestinal loads on meal-eating patterns. Journal of Comparative and Physiological Psychology, 1969, 69, 101-106.

DAvies, R. F. Long- and short-term regulation of feeding patterns in the rat. Journal of Comparative and Physiological Psychology, $1977,91,574-583$.
Fallon, D. Eatometer: A device for continuous recording of freefeeding behavior. Science, 1965, 148, 977-978.

KisselefF, H. R. Free feeding in normal and "recovered lateral" rats monitored by a pellet-detecting eatometer. Physiology \& Behavior, 1970, 5, 163-173.

Le Magnen, J., \& Devos, M. Metabolic correlates of the meal onset in the free food intake of rats. Physiology \& Behavior, $1970,5,805-814$.

Le Magnen, J., \& Tallon, S. La periodicite spontanee de la prise d'aliments ad libitum du rat blanc. Journale de Physiologie (Paris), 1966, 58, 232-349.

Levitsky, D. A. Feeding patterns of rats in response to fasts and changes in environmental conditions. Physiology \& Behavior, $1970,5,291-300$.

Morrison, S. D., \& Coffey, N. F. Feeding activity and feeding efficiency as distinct modes of change in food intake. Journal of Applied Physiology, 1973, 34, 268-270.

PANSKePP, J. Reanalysis of feeding patterns in the rat. Journal of Comparative and Physiological Psychology, 1973, 82, 78-94.

Thомаs, D. W., \& MaYen, J. Meal taking and regulation of food intake by normal and hypothalamic-hyperphagic rats. Journal of Comparative and Physiological Psychology, 1968, 66, 642-653.

Strohmayer, A. J., Silverman, G., \& Grinker, J. A. A device for the continuous recording of solid food ingestion. Physiology \& Behavior, 1980, 24, 789-791.

Yanura, S., \& Suzuki, T. Eating pattern of morphine dependent rats. Japanese Journal of Pharmacology, 1979, 29, 753-762.

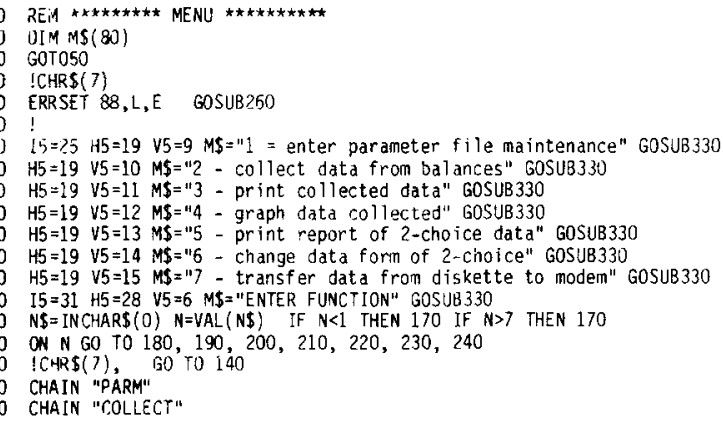

Part 1

?00 CHA TN "PRINT"

210 CHAIN "GRAPH"

220 CHAIN "2-CHOICE"

230 CHAIM "DATAFORM"

240 CHAIN "MODEM"

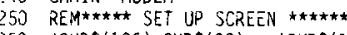

260 !CHRS(126), CHRS(28), !CHR\$(126), CHR\$(25),

270 !TAB (23), "ANIMAL DATA COLLECTION SYSTEM"

280 ! TAB (17), "U S FISH \& WILDLIFE, DENVER, COLORADO"

290 ICHR\$( 300 RETURN

310 REM * POSITION OIRSOR \& PRINT MS *

320 !CHR\$ ( 126$)$, CHRS $(15)$

330 ICHR\$(126), CHR \$(17), CHR\$(H5-1), CHR \$ V5-1), M\$," "

340 D=EAM $(10769)+($ EXAM $(10770)+2 j 6)$ FILI 0,0

350 IF $E=0$ THEN 370 IF $15=31$ THEN 370 E=0 H5=62 M\$="

370 RETLRN

Part 2

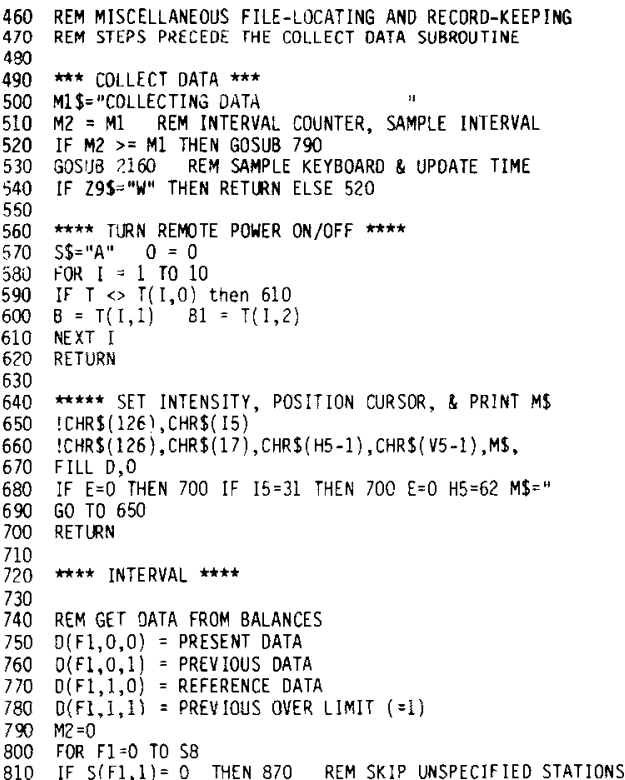

